\title{
A Frequency Reconfigurable Compact Planar Inverted-F Antenna for Portable Devices
}

\author{
Adnan Ghaffar $\left(\mathbb{D},{ }^{1}\right.$ Ahsan Altaf $\mathbb{D D}^{2}$, Aayush Aneja $\mathbb{D}^{1},{ }^{1}$ Xue Jun Li $\mathbb{D}^{1},{ }^{1}$ Salahuddin Khan, ${ }^{3}$ \\ Mohammad Alibakhshikenari $\left(\mathbb{0},{ }^{4}\right.$ Francisco Flalcone $\mathbb{C}^{5},{ }^{5,6}$ and Ernesto Limiti ${ }^{7}{ }^{7}$ \\ ${ }^{1}$ Department of Electrical and Electronic Engineering, Auckland University of Technology, Auckland 1010, New Zealand \\ ${ }^{2}$ INZA Research Laboratory for Electromagnetic and Microwave Engineering, Multan 60600, Pakistan \\ ${ }^{3}$ Department of Electrical Engineering, College of Engineering, King Saud University, Riyadh, Saudi Arabia \\ ${ }^{4}$ Department of Signal Theory and Communications, Universidad Carlos III de Madrid, 28911 Leganés, Madrid, Spain \\ ${ }^{5}$ Department of Electrical, Electronic and Communication Engineering, Public University of Navarre, Navarra, \\ Pamplona 31006, Spain \\ ${ }^{6}$ Institute of Smart Cities, Public University of Navarre, Pamplona 31006, Navarra, Spain \\ ${ }^{7}$ Electronics Engineering Department, University of Rome "Tor Vergata", Via Del Politecnico 100133, Rome, Italy
}

Correspondence should be addressed to Mohammad Alibakhshikenari; mohammad.alibakhshikenari@uc3m.es

Received 1 September 2021; Accepted 29 December 2021; Published 19 January 2022

Academic Editor: Francesco D'Agostino

Copyright (C) 2022 Adnan Ghaffar et al. This is an open access article distributed under the Creative Commons Attribution License, which permits unrestricted use, distribution, and reproduction in any medium, provided the original work is properly cited.

In this paper, a low-profile, compact size, inexpensive, and easily integrable frequency reconfigurable antenna system is proposed. The proposed antenna consists of an inverted-F shape antenna, capacitors, and switching PIN diodes. The designed antenna element is fabricated on easy available and less expensive FR-4 substrate $\left(\varepsilon_{\mathrm{r}}=4.4, \tan \delta=0.02\right)$. The switching diodes are incorporated within the radiating structure of the antenna design, and by changing the different states of PIN diodes, frequency reconfigurable response is achieved. While adjusting the different states of the diodes, the antenna resonates between $0.841 \mathrm{GHz}$ and $2.12 \mathrm{GHz}$ and covers six different frequency bands. The proposed system has compact size of $44 \times 14 \times 3.2 \mathrm{~mm}^{3}$. The gain of the antenna is between 1.89 and $2.12 \mathrm{dBi}$. The measurement results shows the good agreement with simulated results for different key performance parameters. Additionally, the proposed antenna shows omni-directional far-field characteristics for various different frequencies.

\section{Introduction}

Recently, there is a high demand of low-profile, efficient, compact, high-speed, planar, inexpensive, and easily integrable devices [1]. These devices have various applications in different roles within modern telecommunication industry. Antenna is an inevitable part of advances communication systems and plays an increasingly important role in modern electronic devices. They are mostly used for applications requiring constant functional properties, such as fixed polarization, beam-width, far-field characteristics, and so on. However, antenna systems with such attributes (constant functional properties) may increase the complexity of the circuitry and decrease the efficiency. Moreover, integration of multiple radios and the antenna systems within a single device may degrade the performance of the system as well. Therefore, it is believed that to support the challenging characteristics, for instance, high data rates, high bandwidths, and low latency, of modern wireless communication systems, there is a requirement of multi-functional, low-cost, compact, and easy to fabricate and integrate antenna systems which must address these challenges and provide additional services without increasing the complexity and size of the circuitry. In addition, enhancement in devices, components, and subsystems will create new challenges. To address these demands, it will be necessary and reasonable to design a flexible, compact, inexpensive, easily controllable, and adjustable antenna system. 
One possible solution will be to use reconfigurable antennas. These antennas offer effective and promising solutions to various different challenges and also help to improve the efficiency of the system. In addition, they are compact in size, low-cost, and easily integrable. It is worthy to mention that the reconfigurable behavior is achieved by changing the resonant frequency, polarization, and radiation characteristics of the system. In literature, different techniques are used to design the reconfigurable antennas using PIN diode [2-4], RF-MEMS [5], varactor diode [6, 7], different smart materials [8], and optical switches [9].

The main purpose of this work is to design a frequency reconfigurable antenna that must be compact, simple, and easy to fabricate and integrate. To meet the goal of the project, two PIN diodes are used to obtain the frequency reconfigurable behavior. By using ON/OFF operation of diodes, the length of the radiating element is varied, and as a result, the antenna resonates at different frequencies. Before presenting this work, a detailed literature review is conducted to provide readers a brief summary of the existing works.

\section{Related Work}

In literature, the existing works include various different feeding networks and impedance matching circuits incorporated with the reconfigurable antenna that not only increases the complexity of the system but also leads to large size and low efficiency. A T-shaped feeding strip with T-shaped parasitic elements system is used to cover low bands (GSM 850/900) and high bands (GSM 1800/1900/UMTS 2100/LTE $2300 / 2500$ bands) in [10]. However, it fails to represent the behavior of the PIN diode using copper strip, and computed and experimental results showed greater than $-10 \mathrm{~dB}$ impedance matching for the lower bands. In [11], a frequency reconfigurable antenna for multi-band applications was presented. The proposed antenna design is implemented on an FR-4 substrate layer, and two PIN diodes were used to cover three operating modes, i.e., IFA, monopole, and loop mode. In another work [12], a frequency reconfigurable PIFA antenna using defected ground structure (DGS) was proposed [12]. Three PIN diodes were used, and their positions were optimized using genetic algorithm (GA) to obtain three different operating frequencies, namely, $2.1 \mathrm{GHz}, 2.4 \mathrm{GHz}$, and $3.5 \mathrm{GHz}$, but it suffers from narrow bandwidth and large size. In [13], a microstrip patch antenna with slots in the ground plane was designed to cover frequencies between $2.2 \mathrm{GHz}$ and $6 \mathrm{GHz}$. The authors used SPICE model of PIN diode in CST software to analyse the real impact of voltage on the performance of the antenna. This antenna resonated at ten different frequencies but suffers from the large size.

A cedar-shaped reconfigurable antenna to cover WiMAX, Bluetooth, GPS, and WLAN band was reported in [14]. To achieve reconfigurable behavior, a combination of PIN diode and three pairs of varactor diodes were used. The antenna became lossy due to large number of varactor diodes and had large antenna size. In another work [15], a coupled-fed loop antenna to cover octa-band for LTE smartphone was proposed. Low modes were achieved with the combination of loop mode of $0.5 \lambda$ and chip capacitor, and the antenna was operating at the high band by using the combination of $1 \lambda, 1.5 \lambda$, and $2 \lambda$ modes with $0.5 \lambda$ mode of coupling loop. However, this antenna showed $-6 \mathrm{~dB}$ reflection coefficient for lower modes.

A compact frequency reconfigurable PIFA antenna based on nested slots was designed in [16]. In the first case, a multi-band antenna was designed without any RF switch with large antenna area. In the second case, two switching diodes were used to achieve the different frequencies with $60 \%$ reduction in the antenna size. The antenna resonated between $0.77 \mathrm{GHz}$ and $3.55 \mathrm{GHz}$ frequency band, but it showed $-6 \mathrm{~dB}$ reflection coefficient for all desirable frequencies. In [17], an E-shaped wearable dipole for IoT applications was proposed. A detailed study was conducted for different bending conditions. However, the proposed antenna design suffers from large size constraint. A CPW-fed multi-band frequency reconfigurable antenna for wireless applications was presented in [18]. Four PIN diodes were used to obtain frequency reconfigurable behavior for $2 \mathrm{GHz}$ to $10 \mathrm{GHz}$ frequency range. It is stated that the biasing line was used for PIN diodes, capacitor, and inductor. However, copper strip was used as a lumped switch instead of real PIN diodes. In [19], an antenna with differential reconfigurable capability was designed to cover sub-6 GHz 5G and WLAN application. The antenna structure consists of two dipoles, PIN diodes, mode switching system, and feeding structure. The antenna measurement results have good agreement with simulated results, but the size of the antenna is large. In a similar study [20], a low-profile simple monopole antenna to operate in five modes, covering 9 frequencies, was proposed. The presented antenna consists of simple L-shaped monopole with truncated metallic ground plane. This is done to achieve high gain and high efficiency, but the proposed antenna is large in size. A frequency reconfigurable MIMO antenna for LTE and 5G applications was presented in [21]. The proposed MIMO antenna system consists of two meandered radiation arms connected with a $50 \Omega$ feedline. The system resonates at $2.4 \mathrm{GHz}$ and $3.5 \mathrm{GHz}$ with an interelement isolation better than $12 \mathrm{~dB}$. This system also suffers from large size constraint.

In summary, a detailed literature review was conducted, and it was found that most of the works suffered from large size, complexity, and narrow bandwidth, and this is the motivation behind this work. Therefore, it is reasonable to propose an antenna system that can address these issues and provide a smart solution.

\section{Proposed Antenna Design}

The design, working principle, switching method, and parametric studies of the designed antenna are discussed in this section. The basic design methodology of the designed antenna has been presented previously [22]. The proposed system consists of $\mathrm{F}$ and I-shaped radiating elements. This system is etched on a double-sided widely available FR-4 substrate $\left(\varepsilon_{\mathrm{r}}=4.4, \tan \delta=0.02\right)$, as shown in Figure 1. The ground plane is on the other side of the board, and the thickness of the substrate and the metal is $3.2 \mathrm{~mm}$ and $0.035 \mathrm{~mm}$, respectively. Multiple shorting vias are used to 


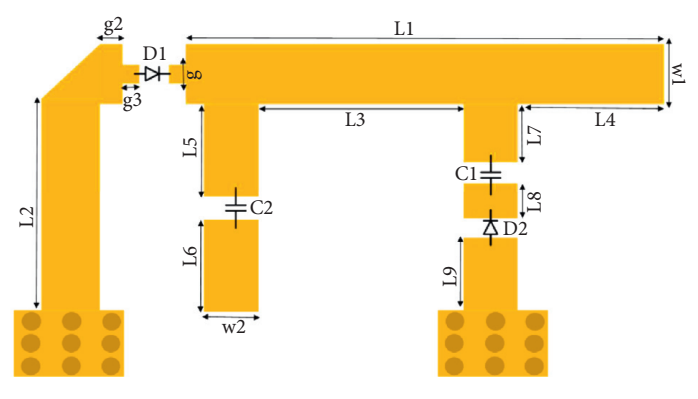

(a)

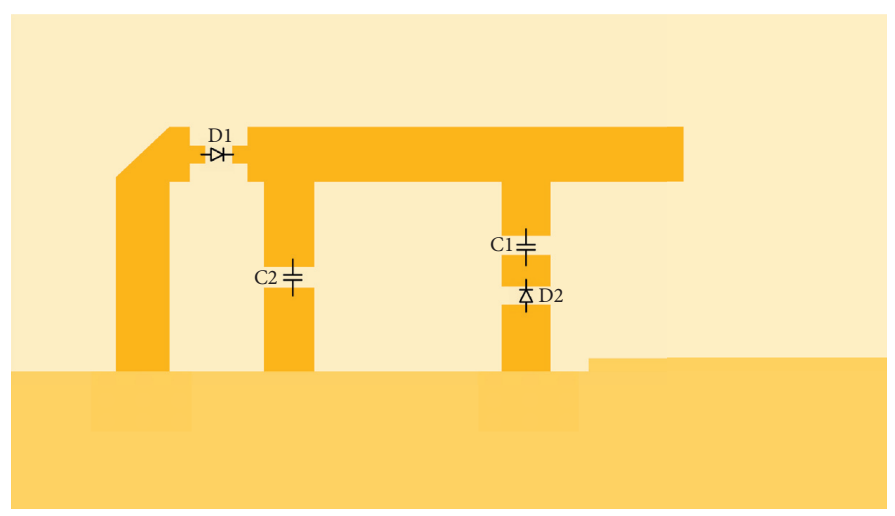

(b)

Figure 1: Prototype of the proposed antenna system. (a) Detailed dimensions. (b) Antenna system.

connect the ground plane and the radiating element. Further, a ground plane is also used to improve impedance matching. A $50 \Omega$ SMA connector is used to feed the system. Note that the shorting vias, ground plane, and the radiating elements are made up of copper with a conductivity of $5.87 \times$ $10^{7} \mathrm{~S} / \mathrm{m}$. The dimensional parameters of the designed antenna are depicted in Table 1 . The complete structure of the proposed system is depicted in Figure 1. From Figure 1(b), it can be seen that the system has PIN diodes, $D_{1}$ and $D_{2}$, capacitors, $C_{1}$ and $C_{2}$, and a ground plane. It is worthy to mention that the different states of PIN diodes are used to achieve the required response at desired frequencies. Note that the diodes are located on the radiation elements, i.e., $D_{1}$ is inserted between the long radiation strip $\left(L_{1}\right)$ and $L$ shaped strip $\left(L_{2}\right)$, and both are connected with the ground plane by vias. Similarly, $D_{2}$ is placed between the strips $\left(L_{8}\right.$ and $L_{9}$ ) and the cathode of $D_{2}$ and then connects to shorting vias. By using different combinations of ON/OFF states of the PIN diodes, the proposed antenna system operates at four different states, where three states provide a closed path for the current to flow within the system. In state $1, D_{1}$ is ON and $D_{2}$ is OFF; therefore, the total length $\left(L_{1}+L_{2}+L_{5}+\right.$ $L_{6}+L_{7}$ ) of the antenna becomes $62.45 \mathrm{~mm}$, and it covers GSM 850/900 frequency bands. In state $2, D_{1}$ is OFF and $D_{2}$ is ON; therefore, the total length $\left(L_{1}+L_{5}+L_{6}+L_{7}+L_{8}+\right.$ $L_{9}$ ) of the antenna becomes $52.7 \mathrm{~mm}$ and the antenna operates in loop mode covering UMTS 2100, GLONASS 1616, PCS 1900, and DCS 1800 frequency bands. Finally, in state 3 , when both diodes are OFF, the total length $\left(L_{1}+\right.$ $L_{5}+L_{6}+L_{7}$ ) of the antenna becomes $49.8 \mathrm{~mm}$ and antenna resonates to cover GSM 900 and UMTS 2100 bands.

3.1. Switching Techniques. In modern portable devices, switches play an increasingly important role to provide an extra degree of freedom to shift between different modes of operations. Therefore, in this work, PIN diodes are used as a switch. PIN diodes have unique advantages, for example, fast switching speed, better isolation, low power handling, excellent repeatability, and long life as compared to the other RF switches, such as MEMS and varactor diode. PIN diode behaves as a currentcontrolled resistor within microwave frequency range. In this
TABLE 1: Dimensions of the proposed antenna.

\begin{tabular}{lccc}
\hline Parameters & Values $(\mathrm{mm})$ & Parameters & Values $(\mathrm{mm})$ \\
\hline$L$ & 120 & $L_{1}$ & 37.6 \\
$W$ & 60 & $L_{2}$ & 12.65 \\
$L_{g}$ & 120 & $L_{3}$ & 16.5 \\
$W_{g}$ & 43.25 & $L_{4}$ & 17.2 \\
$W_{1}$ & 2 & $L_{5}$ & 6.65 \\
$W_{2}$ & 2 & $L_{6}$ & 2.3 \\
$g$ & 0.5 & $L_{7}$ & 3.25 \\
$g_{2}$ & 0.4 & $L_{8}$ & 0.5 \\
$g_{3}$ & 0.7 & $L_{9}$ & 2.4 \\
$g_{4}$ & 0.4 & & \\
\hline
\end{tabular}

work, SMP1345 PIN diode from Skyworks has been used. This diode is suitable for $10 \mathrm{MHz}$ to $6 \mathrm{GHz}$ frequency range applications. The working principle is as follows.

When a PIN diode is forward biased, it acts like a conventional $\mathrm{PN}$-junction diode which allows current in one direction and blocks in the other direction. The circuit equivalent models for forward-biased and reverse-biased conditions and biasing circuit are shown in Figure 2. It is worth to mention that, when the diode is in ON state, it can be represented as a series combination of a resistor of $5 \Omega$ and an inductor of $0.7 \mathrm{nH}$. Note that the value of the resistor is very small that allows current to pass through the radiating element, thus resulting in change of the resonant frequency. In other scenario, when the diode is in OFF state, the equivalent circuit model consists of a parallel combination of a resistor of $5 \mathrm{k} \Omega$ and a capacitor of $0.2 \mathrm{pF}$ in series with an inductor of $0.7 \mathrm{nH}$. A high-value resistor restricts the current flow through the radiation element. For biasing circuit, a $100 \mathrm{pF}$ capacitor, $C_{1}$, is used to block DC component between $D_{1}$ and the probe feed. For similar reasons, another capacitor $C_{2}$ is used between $D_{2}$ and I-shaped radiation element, and a biasing voltage of $0.89 \mathrm{~V}$ and $0 \mathrm{~V}$ is applied to PIN diodes for ON and OFF states, respectively.

3.2. Parametric Studies. To understand the behavior and impact of different parameters of the antenna, a parametric study was conducted to optimize and achieve desirable response of the system. 


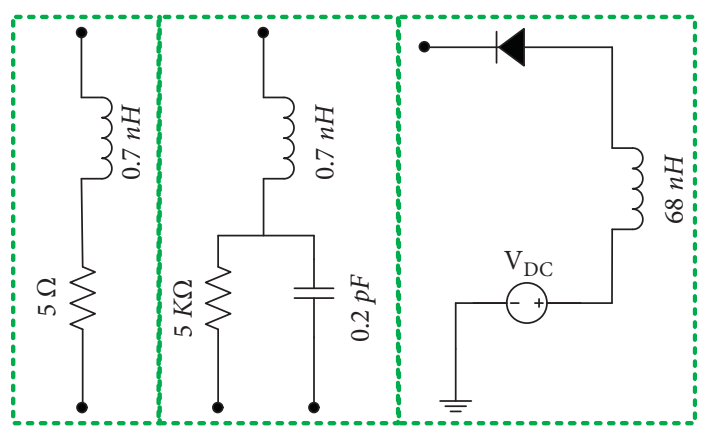

(a)

(b)

(c)

FIgURE 2: Equivalent model of diode for (a) ON state and (b) OFF state and (c) biasing circuit.

First, the width $(\mathrm{g})$ is varied from $1 \mathrm{~mm}$ to $2 \mathrm{~mm}$ with an increase of $0.5 \mathrm{~mm}$ while other parameters are kept constant. Here, three different scenarios are considered, first, $D_{1}$ is $\mathrm{ON}$ and $D_{2}$ is OFF, second, $D_{1}$ is OFF and $D_{2}$ is ON, and third, both diodes are OFF. Considering Figure 3, a few conclusions can be drawn as follows:

(1) For scenario 1, the proposed antenna shows narrow bandwidth at $0.8 \mathrm{GHz}$ and does not cover GSM 950 frequency band.

(2) For scenario 2, the proposed antenna shows narrow bandwidth at $2 \mathrm{GHz}$ and does not cover UMTS 2100 frequency band. In addition, a lossy behavior is observed when the width is $2 \mathrm{~mm}$.

(3) When both diodes are OFF, the designed antenna resonates in dual-band mode at $1 \mathrm{GHz}$ and $1.9 \mathrm{GHz}$.

Similarly, the variations in the reflection coefficient are studied by changing the length $\left(L_{1}\right)$ while keeping other parameters same. Like the previous study, here again three different cases are studied and the length is varied between $27.6 \mathrm{~mm}$ and $37.6 \mathrm{~mm}$ with an increase of $5 \mathrm{~mm}$. From Figure 4, the following observations can be made:

(1) For case 1, the proposed antenna resonates at GSM $850 / 900$ bands for the upper value $(37.6 \mathrm{~mm})$, and for other two values $(27.6 \mathrm{~mm}$ and $32.6 \mathrm{~mm})$, it does not resonate at the desirable bands (GSM 850/900).

(2) For case 2, the proposed antenna shows narrow bandwidth for lower two values $(27.6 \mathrm{~mm}$ and $32.6 \mathrm{~mm}$ ) of the length, and for the upper value $(37.6 \mathrm{~mm})$, it has a bandwidth of $600 \mathrm{MHz}$ and covers the UMTS 2100 frequency bands.

(3) When both diodes are OFF, the resonance at the lower band is slightly shifted and shows a desirable reflection coefficient for different values of the length at both frequency bands.

\section{Results and Discussion}

Different key performance parameters of the proposed antenna design are discussed in detail in this section. The fabricated prototype of the proposed antenna design is shown in Figure 5. To drive PIN diode, power is supplied using connecting wires and these connecting wires are connected to the back plane to avoid the disturbance within the radiation pattern. The PIN diode consumes $10 \mathrm{~mA}$ current for the forward-biased voltage of $0.89 \mathrm{~V}$. For the reverse-biased condition, the voltage provided is assumed to be zero.

The measured and simulated reflection coefficient comparison for three different combinations of diodes states is shown in Figure 6. When both diodes are OFF as shown in Figure 6(a), the antenna operates in dual-band mode at $1.94 \mathrm{GHz}$ to $2.12 \mathrm{GHz}$ covering UMTS 2100 and GSM 900/ 950 bands. On the other hand, when $D_{1}$ is $\mathrm{ON}$ and $D_{2}$ is OFF, the frequency is shifted towards the lower band, resonating at $0.841 \mathrm{GHz}$ to $0.964 \mathrm{GHz}$ covering GSM 850/ 900 bands, as shown in Figure 6(b). When $D_{1}$ is OFF and $D_{2}$ is ON, it is observed that the antenna covers DCS 1800, PCS 1900, and UMTS 2100 bands, as shown in Figure 6(c). The measured results are slightly shifted as compared to the simulated results, and this is because of the parasitic impedance due to PIN diodes, dielectric constant, loss tangent, and solder mask effects. It is worthy to mention that overall the results are in good agreement.

The current distribution of the proposed antenna design is explained in Figure 7 to better understand the working principle at the fundamental level. These current distributions are shown for three different combinations of the diode states at $0.85 / 0.9 \mathrm{GHz}, 1.6 \mathrm{GHz}, 1.8 \mathrm{GHz}, 1.9 \mathrm{GHz}$, and $2.1 \mathrm{GHz}$. When $D_{1}$ is $\mathrm{ON}$ and $D_{2}$ is $\mathrm{OFF}$, the current flows in F-shaped radiated element through feed, and also, it is almost the quarter wavelength for GSM 850/900 bands, as shown in Figure $7(\mathrm{a})$. On the other hand, when $D_{1}$ is OFF and $D_{2}$ is $\mathrm{ON}$, the surface current flows in I-shaped and long-strip element from feed, as shown in Figure 7(b). Note that, in this case, four different frequencies are covered $(1.54 \mathrm{GHz}$ to $2.13 \mathrm{GHz})$. Finally, when both diodes are OFF, the surface current distribution is illustrated in Figure $7(\mathrm{c})$. In this case, the current mainly flows in long-strip and I-shaped element.

The simulated and measured far-field characteristics are shown in Figure 8. The proposed antenna shows dipole-like omni-directional patterns. In Figures 8(a) and 8(b), the radiation characteristics for $\mathrm{E}$ and $\mathrm{H}$ planes are shown when both diodes are OFF. In Figures 8(c) and 8(d), the far fields are illustrated when $D_{1}$ is OFF and $D_{2}$ is ON. The radiation patterns for the both planes when $D_{1}$ is $\mathrm{ON}$ and $D_{2}$ is $\mathrm{OFF}$ are shown in Figures 8(e) and 8(f). 


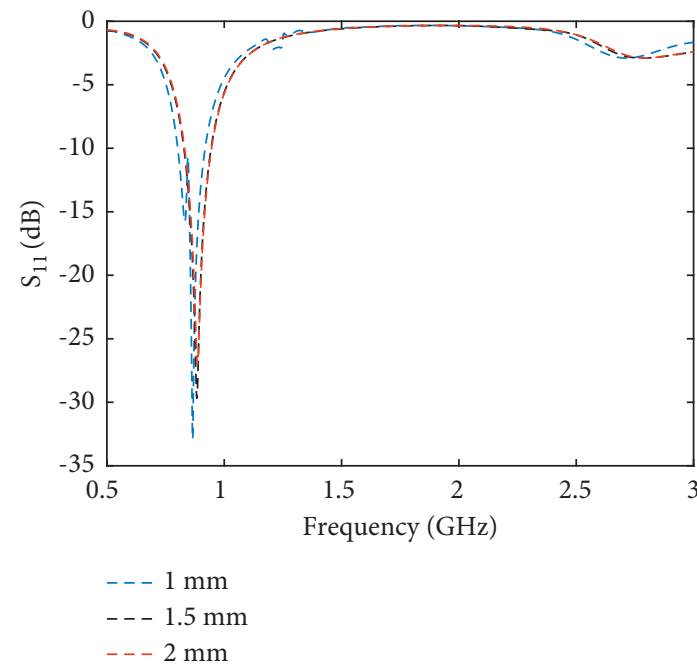

(a)

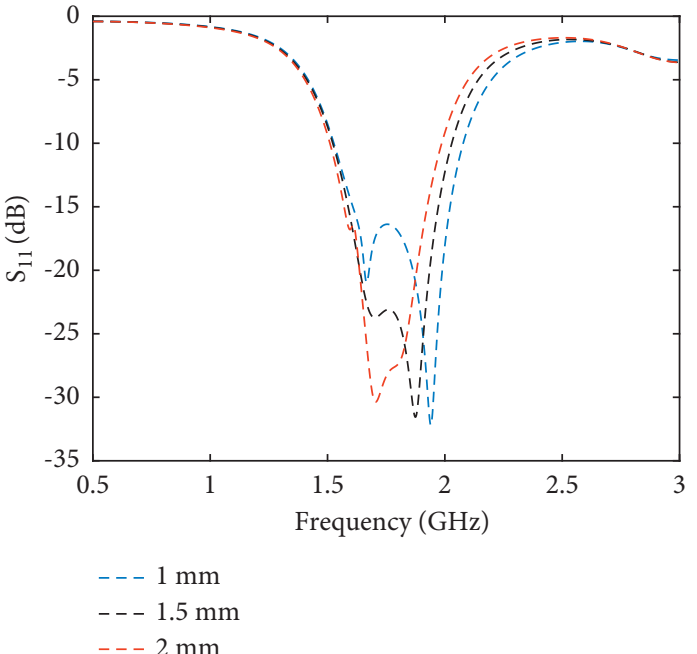

(b)

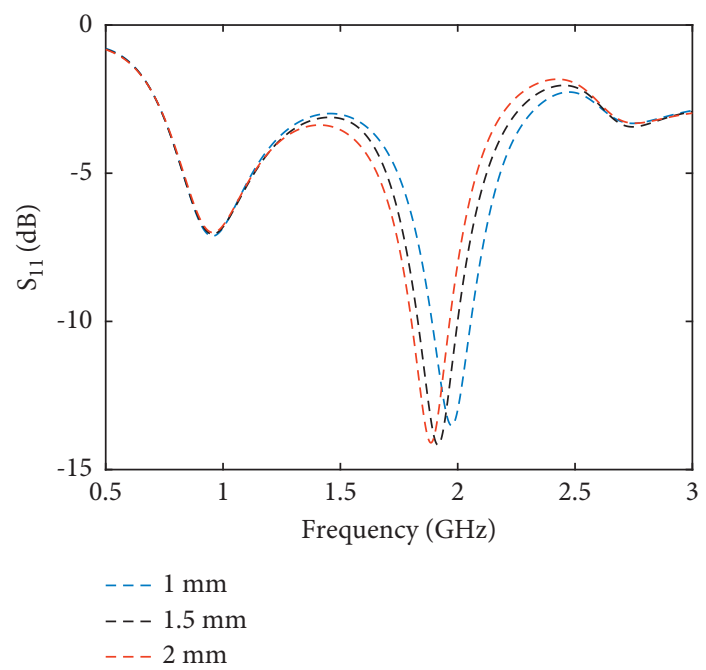

(c)

Figure 3: Study on width (g), when (a) $D_{1}$ is ON and $D_{2}$ is OFF; (b) $D_{1}$ is OFF and $D_{2}$ is ON; and (c) both diodes are OFF.

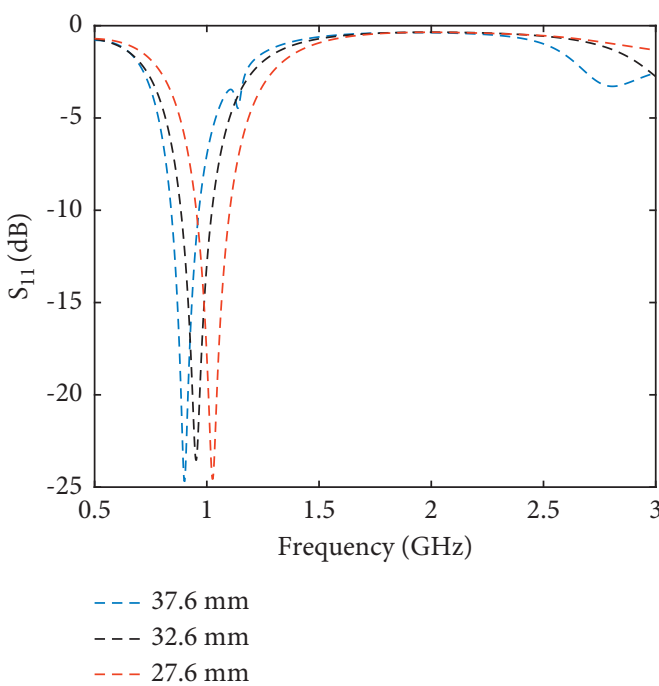

(a)

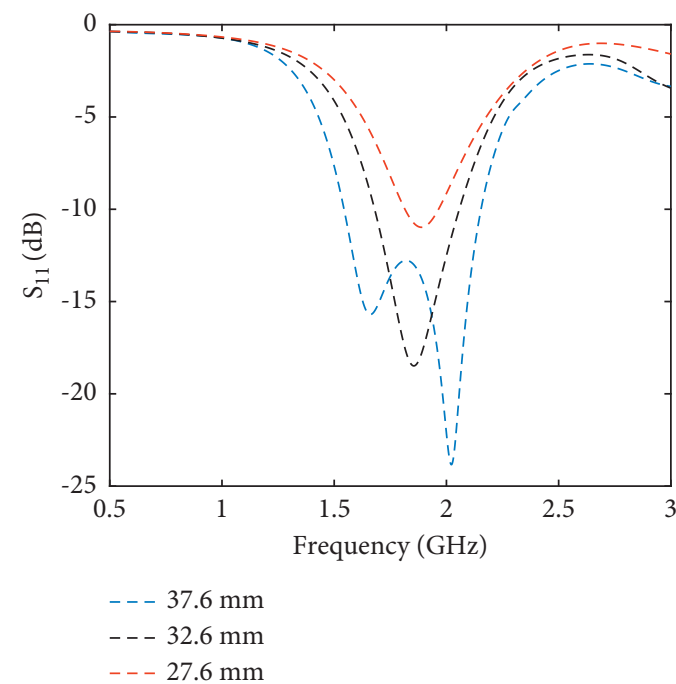

(b)

Figure 4: Continued. 


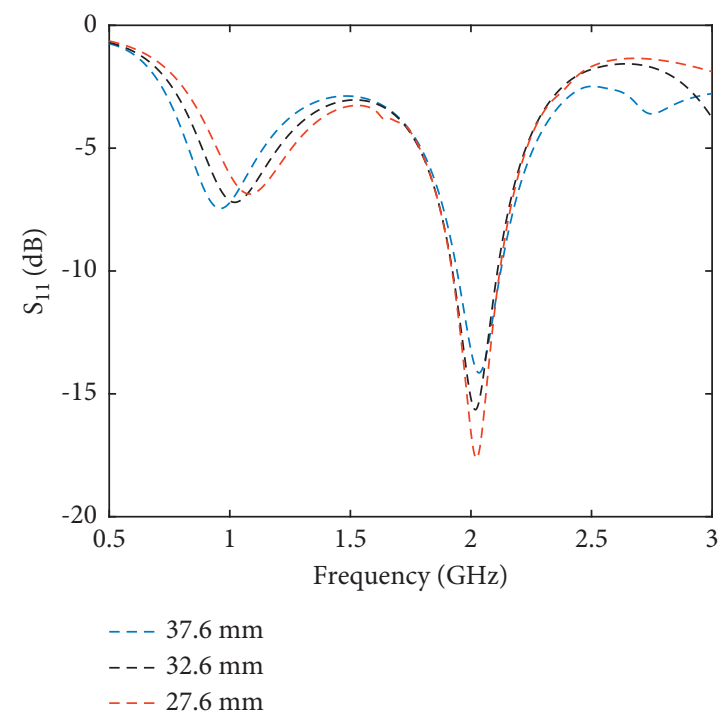

(c)

Figure 4: Study on the length $\left(L_{1}\right)$, when $(\mathrm{a}) D_{1}$ is ON and $D_{2}$ is OFF; (b) $D_{1}$ is OFF and $D_{2}$ is ON; and (c) both diodes are OFF.

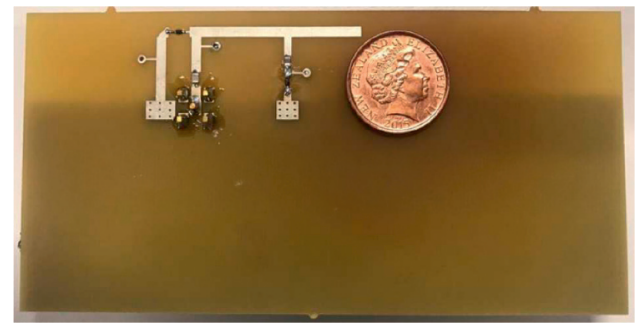

(a)

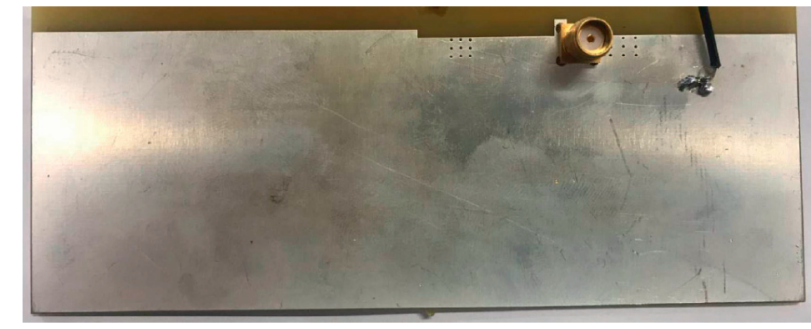

(b)

FIgURE 5: Proposed antenna prototype. (a) Front side. (b) Back side.

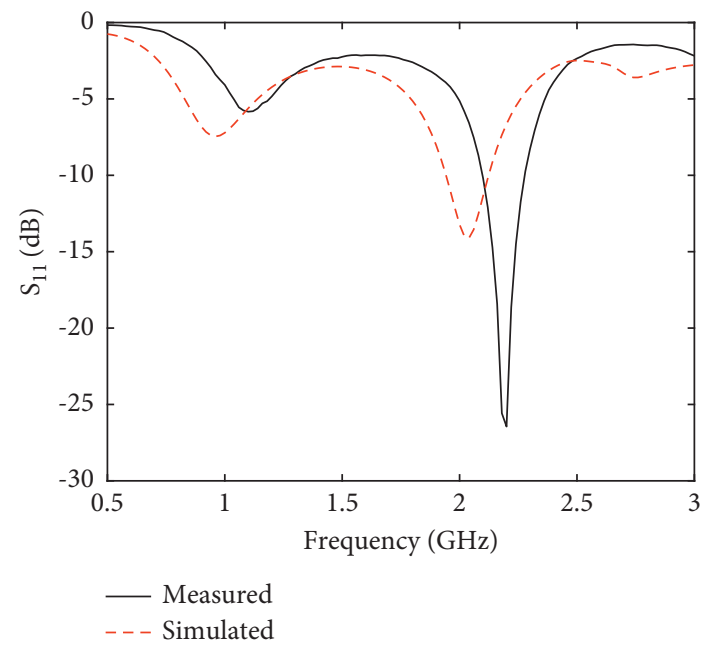

(a)

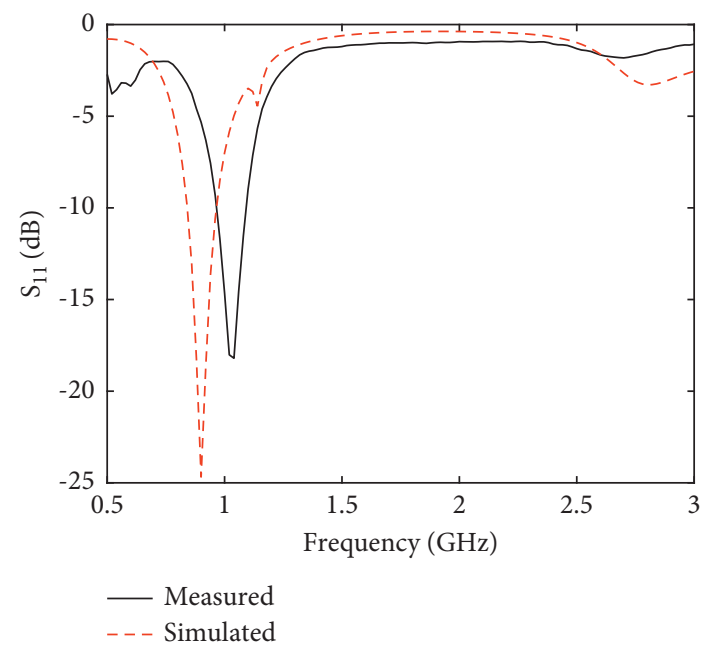

(b)

Figure 6: Continued. 


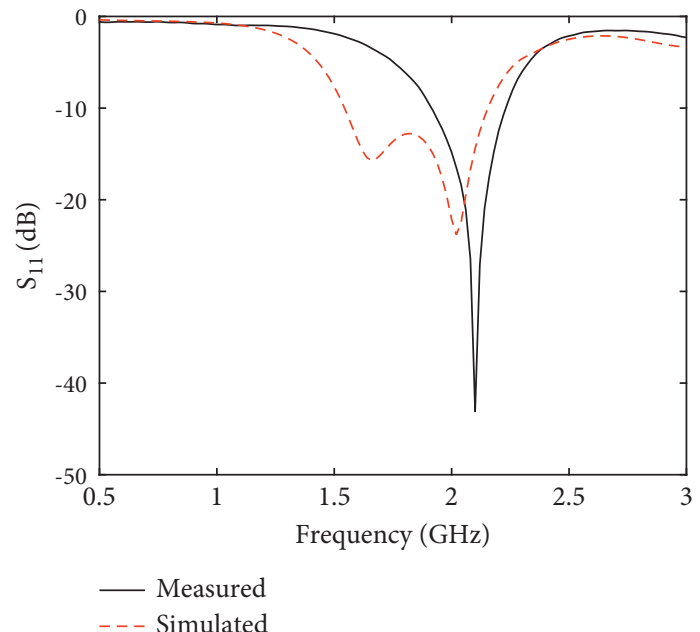

(c)

Figure 6: Simulated and measured reflection coefficients for different states of PIN diodes, when (a) both diodes are OFF; (b) $D_{1}$ is ON and $D_{2}$ is OFF; and (c) $D_{1}$ is OFF and $D_{2}$ is ON.

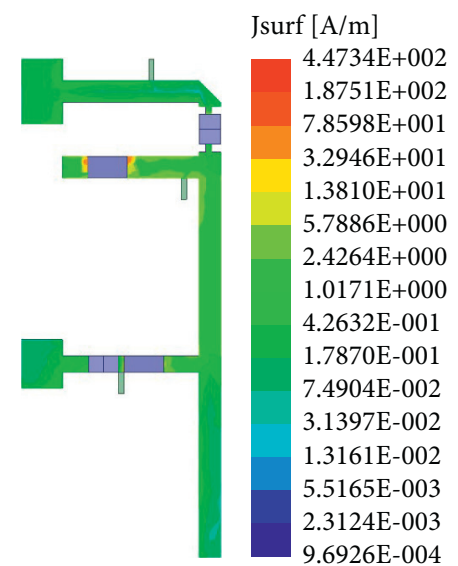

(a)

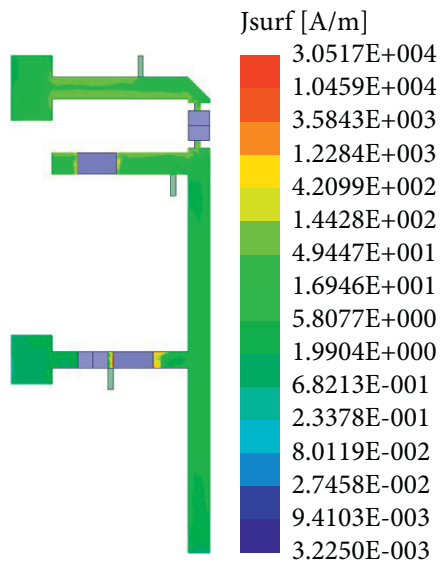

(b)

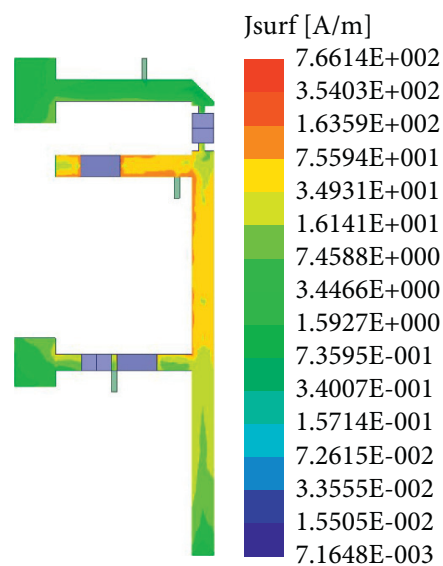

(c)

FIgure 7: Current distribution, when (a) $D_{1}$ is ON and $D_{2}$ is OFF; (b) $D_{1}$ is OFF and $D_{2}$ is ON; and (c) both diodes are OFF.

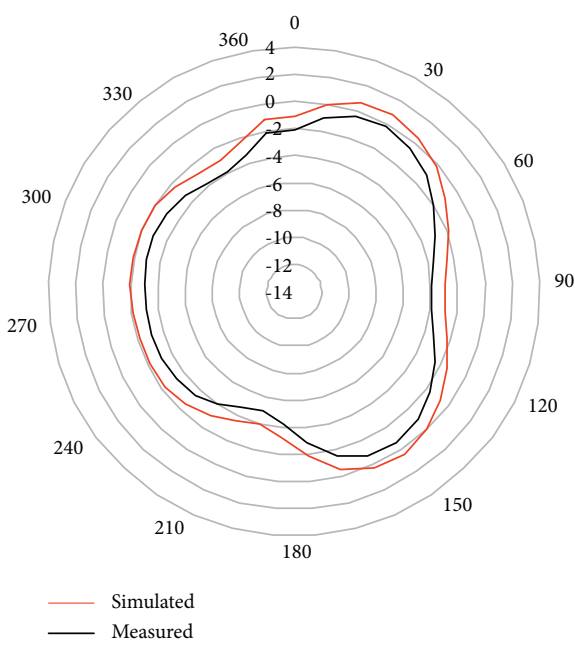

(a)

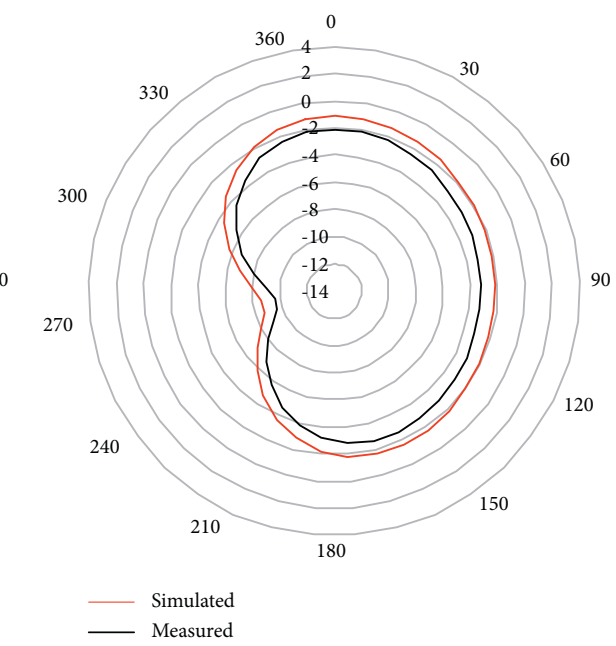

(b)

Figure 8: Continued. 


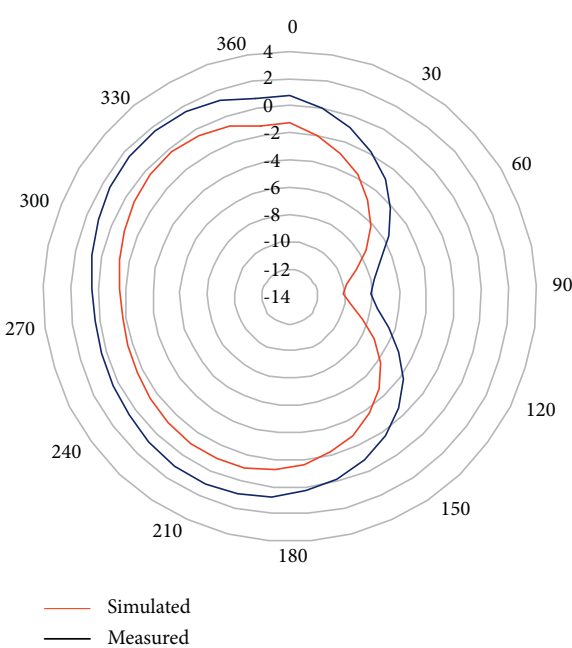

(c)

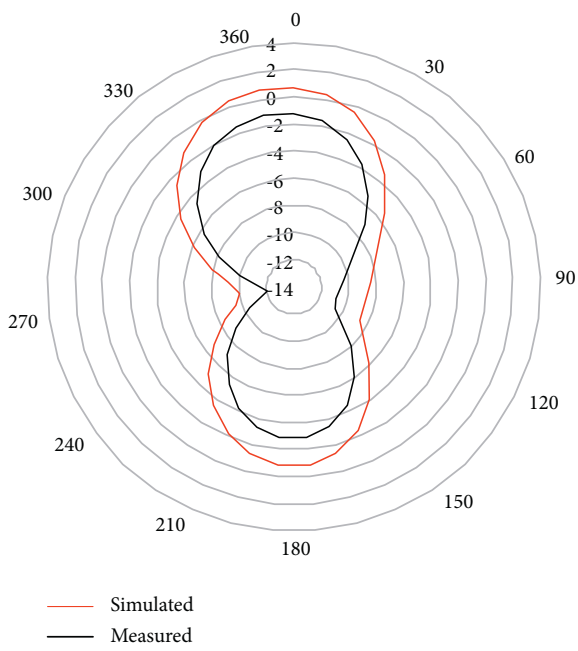

(e)

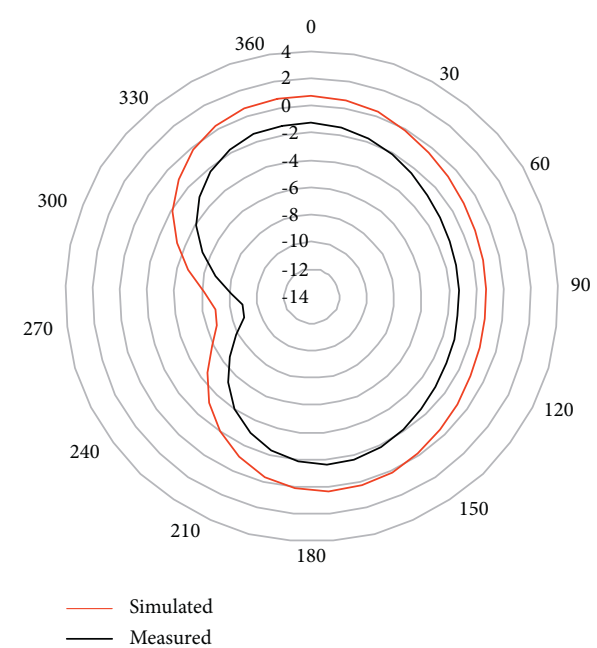

(d)

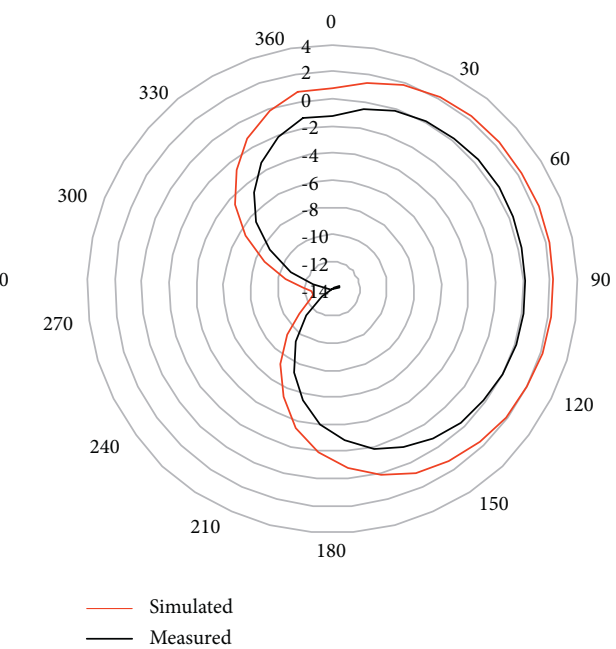

(f)

Figure 8: Simulated and measured 2-D radiation patterns for both $\mathrm{E}$ and $\mathrm{H}$ planes of the proposed antenna design, when (a, b) both diodes are OFF; (c, d) $D_{1}$ is OFF and $D_{2}$ is ON; and $(e, f) D_{1}$ is ON and $D_{2}$ is OFF.

TABLE 2: Comparison with other designs.

\begin{tabular}{|c|c|c|c|c|c|}
\hline Ref. & Antenna size $\left(\mathrm{mm}^{2}\right)$ & Working frequency $(\mathrm{GHz})$ & No. of switches & Substrate & Gain $(\mathrm{dBi})$ \\
\hline$[12]$ & $63.5 \times 33.5$ & $2.1,2.4,3.5$ & 3 & FR-4 & $0.48-4.33$ \\
\hline [13] & $50 \times 45$ & $2.2-6$ & 2 & FR-4 & $0.4-5.8$ \\
\hline [14] & $65 \times 60$ & $1.45-4.6$ & 6 & FR-4 & N.A \\
\hline [17] & $62 \times 46$ & $2.45,5.25,5.75$ & N.A & Denim & $1.26-2.64$ \\
\hline$[18]$ & $40 \times 60$ & $2-10$ & 4 & FR-4 & $0.64-2.5$ \\
\hline [19] & $50 \times 50$ & $3.5,5.5$ & 4 & FR-4 & $1.5-4.2$ \\
\hline [20] & $40 \times 30$ & $1.8,2.1,2.6,3.5,4.8,5,5.6,6.4,6.5$ & 4 & FR-4 & $1.25-3.6$ \\
\hline [21] & $120 \times 60$ & $2.4,3.5$ & 4 & RO4003C & $3.7-4.2$ \\
\hline This work & $44 \times 14$ & GSM 850, GSM 900, UMTS 2100 & 2 & FR-4 & $1.89-2.12$ \\
\hline
\end{tabular}

To further demonstrate the contribution of this work, a detailed comparison of the proposed work with available literature for different performance and geometrical parameters is illustrated in Table 2. Table 2 shows the comparison in terms of antenna size, substrate, resonant frequencies, and the number of switches.

\section{Conclusion}

In this work, a frequency reconfigurable antenna for GSM 850/ 900 and UMTS 2100 frequency bands is proposed. The proposed antenna system consists of a radiating element, vias, and two PIN diodes. This system is designed on an FR-4 substrate, and 
PIN diodes are used to achieve reconfigurable response. The design, working principle, and effects of different parameters are discussed. To verify the simulated results, a prototype is fabricated, and it is found that the experimental and the measured results are in good agreement. Different key performance parameters, such as reflection coefficient, far-field radiation patterns, and current distribution, are presented. Based on results, it is believed that the requirements of several wireless standards are met. The main feature of the proposed antenna system is that it is highly compact in size, while demonstrating a performance comparable with existing designs.

\section{Data Availability}

The data used to support the findings of this study are included within the article.

\section{Conflicts of Interest}

The authors declare that they have no conflicts of interest.

\section{Acknowledgments}

This study received funding from Universidad Carlos III de Madrid and the European Union's Horizon 2020 Research and Innovation Programme under Marie Sklodowska-Curie grant 801538 . This study was also partially supported by Ministerio de Ciencia, Innovación y Universidades, Gobierno de España (MCIU/AEI/FEDER, UE) (RTI2018095499-B-C31). Additionally, the authors sincerely appreciate funding from Researchers Supporting Project (RSP2021/58), King Saud University, Riyadh, Saudi Arabia.

\section{References}

[1] A. Iqbal, J. J. Tiang, S. K. Wong, M. Alibakhshikenari, F. Falcone, and E. Limiti, "Miniaturization trends in substrate integrated waveguide (SIW) filters: a review," IEEE Access, vol. 8, pp. 223287-223305, 2020.

[2] A. Ghaffar, X. J. Li, and B.-C. Seet, "Dual frequency band and polarization reconfigurable antenna for mobile devices," in Proceedings of the 2017 IEEE 17th International Conference on Communication Technology (ICCT), pp. 696-700, IEEE, Chengdu, China, October 2017.

[3] A. Iqbal, A. Smida, L. F. Abdulrazak et al., "Low-profile frequency reconfigurable antenna for heterogeneous wireless systems," Electronics, vol. 8, no. 9, Article ID 976, 2019.

[4] W. A. Awan, N. Hussain, S. A. Naqvi et al., "A miniaturized wideband and multi-band on-demand reconfigurable antenna for compact and portable devices," $A E U$ - International Journal of Electronics and Communications, vol. 122, Article ID 153266, 2020.

[5] M. D. Wright, W. Baron, J. Miller, J. Tuss, D. Zeppettella, and M. Ali, "MEMS reconfigurable broadband patch antenna for conformal applications," IEEE Transactions on Antennas and Propagation, vol. 66, no. 6, pp. 2770-2778, 2018.

[6] Z. Ding, R. Jin, J. Geng, W. Zhu, and X. Liang, "Varactor loaded pattern reconfigurable patch antenna with shorting pins," IEEE Transactions on Antennas and Propagation, vol. 67, no. 10, pp. 6267-6277, 2019.

[7] A. Smida, A. Iqbal, M. Selmi, A. A. Althuwayb, and N. K. Mallat, "Varactor diode-based dual-band frequency tunable multiple-input multiple-output antenna," International Journal of RF and Microwave Computer-Aided Engineering, vol. 31, no. 2, Article ID e22519, 2021.

[8] C. Wang, J. C. Yeo, H. Chu, C. T. Lim, and Y.-X. Guo, "Design of a reconfigurable patch antenna using the movement of liquid metal," IEEE Antennas and Wireless Propagation Letters, vol. 17, no. 6, pp. 974-977, 2018.

[9] A. Iqbal and O. A. Saraereh, "A compact frequency reconfigurable monopole antenna for Wi-Fi/WLAN applications," Progress In Electromagnetics Research Letters, vol. 68, pp. 79-84, 2017.

[10] Y. Xu, Y. W. Liang, and H. M. Zhou, "Small-size reconfigurable antenna for WWAN/LTE/GNSS smartphone applications," IET Microwaves, Antennas \& Propagation, vol. 11, no. 6, pp. 923-928, 2017.

[11] X. Zhang, M. Tian, A. Zhan, Z. Liu, and H. Liu, "A frequency reconfigurable antenna for multiband mobile handset applications," International Journal of RF and Microwave ComputerAided Engineering, vol. 27, no. 9, Article ID 21143, 2017.

[12] P. T. Minh, N. T. Duc, P. X. Vu, N. T. Chuyen, and V. Van Yem, "Low profile frequency reconfigurable PIFA antenna using defected ground structure," REV Journal on Electronics and Communications, vol. 7, no. 1-2, 2017.

[13] Y. I. Abdulraheem, G. A. Oguntala, A. S. Abdullah et al., "Design of frequency reconfigurable multiband compact antenna using two PIN diodes for WLAN/WiMAX applications," IET Microwaves, Antennas \& Propagation, vol. 11, no. 8, pp. 1098-1105, 2017.

[14] M. A. Madi, M. Al-Husseini, and K. Y. Kabalan, "Frequency tunable cedar-shaped antenna for WIFI and WIMAX," Progress In Electromagnetics Research Letters, vol. 72, pp. 135-143, 2018.

[15] P. Wang, Y. Shao, D. Huang, and M. A. Basit, "A compact coupled-fed loop antenna for mobile LTE smartphones," International Journal of Antennas and Propagation, vol. 2018, Article ID 8426574, 2018.

[16] F. A. Asadallah, J. Costantine, and Y. Tawk, "A multiband compact reconfigurable PIFA based on nested slots," IEEE Antennas and Wireless Propagation Letters, vol. 17, no. 2, pp. 331-334, 2018.

[17] H. Azeez, H.-C. Yang, and W.-S. Chen, "Wearable triband E-shaped dipole antenna with low SAR for IoT applications," Electronics, vol. 8, no. 6, Article ID 665, 2019.

[18] T. Khan, M. Rahman, A. Akram, Y. Amin, and H. Tenhunen, "A low-cost CPW-fed multiband frequency reconfigurable antenna for wireless applications," Electronics, vol. 8, no. 8, Article ID 900, 2019.

[19] G. Jin, C. Deng, Y. Xu, J. Yang, and S. Liao, "Differential frequency-reconfigurable antenna based on dipoles for Sub-6 $\mathrm{GHz} 5 \mathrm{G}$ and WLAN applications," IEEE Antennas and Wireless Propagation Letters, vol. 19, no. 3, pp. 472-476, 2020.

[20] H. Dildar, F. Althobiani, I. Ahmad et al., "Design and experimental analysis of multiband frequency reconfigurable antenna for $5 \mathrm{G}$ and sub-6 GHz wireless communication," Micromachines, vol. 12, no. 1, 32 pages, 2020.

[21] A. Pant, M. Singh, and M. S. Parihar, "A frequency reconfigurable/switchable MIMO antenna for LTE and early 5G applications," AEU - International Journal of Electronics and Communications, vol. 131, Article ID 153638, 2021.

[22] A. Ghaffar, X. J. Li, and T. Ahmad, "A compact frequency reconfigurable PIFA antenna for heterogeneous applications," in Proceedings of the 2020 IEEE Asia-Pacific Microwave Conference (APMC), pp. 628-630, Hong Kong, Hong Kong, December 2020. 